\title{
Análise do uso e ocupação do litoral de São Gonçalo do Amarante - Ceará - Brasil
}

\author{
Analysis of the coastal use and occupation of São Gonçalo do Amarante - Ceará - Brazil
}

\author{
PORTELA ${ }^{1}$, J. P.; FREIRE ${ }^{2}$, G. S. S.; MORAIS ${ }^{3}$, M. V. A. R. \\ portela_ce@hotmail.com;
}

\begin{abstract}
Resumo
O presente trabalho teve como objetivo ralizaar uma análise do processo de uso e ocupação do litoral do município de São Gonçado do Amarante, aliado aos impactos ambientais, compreendendo as praias de Pecém e Taíba. Primeiramente foram realizadas pesquisas bibliográficas e cartográficas referentes à temática proposta. Foram realizados trabalhos de campo entre os anos de 2014 a 2017, objetivando a obtenção de registros fotográficos e observações, no tocante as modificações impostas pelo homem. Os materiais geocartográficos constaram de imagens de satélites multitemporais e fotografias aéreas de 1965. As etapas de campo foram realizadas nos meses de abril/outubro dos anos de 2013/2016A construção do porto também trouxe mudança na ficionomia da praia do Pecém, como a progradação da área a sotamar da ponta do Pecém, bem como no aumento da ocupação da área ao entorno em virtude de sua atividade. O processo de uso e ocupação na área de estudo está voltado prioritariamente para atividade turística, onde a maioria das estruturas alocou-se em áreas de grande fragilidade ambiental. Tratando-se de uma zona bastante dinâmica, carece de contínuo monitoramento e diagnósticos que possam nortear o processo de ocupação mais ordenada e oferecer maior qualidade de vida para a população existente na região.
\end{abstract}

Palavras-chave: conservação ambiental, desenvolvimento, ambiente praial.

\begin{abstract}
This study analyzed the use and occupation of the beaches of Pecém and Taíba, located in the municipality of São Gonçalo do Amarante, Ceará, with the analysis of the environmental impacts mainly by tourism activities and the implementation of the Port of Pecém. First, bibliographical and cartographic researches were carried out regarding the proposed theme. On next Fieldwork was carried out between 2014 and 2017, aiming at obtaining photographic records and observations, regarding the changes imposed by man. The geocartographic materials used consisted of multitemporal satellite images and aerial photographs of 1965 . Fieldwork was carried out in the months of April/October of the years of 2013/2016. The construction of the port also caused a change in the physiognomy of the Pecém beach, as well as the increase of the area occupied by the area due to its activity. The process of use and occupation in the study area is focused primarily on tourism activity, where most of the structures are located in areas of great environmental fragility. Because of the dynamic area, it needs continuous monitoring and diagnoses that can guide the more orderly occupation process and offer a higher quality of life for the population of the region.
\end{abstract}

Keywords: environmental conservation, development, environment beach.

\section{INTRODUÇÃO}

Nos últimos anos observa-se um acelerado avanço técnico científico aliado ao crescente processo industrial nos países desenvolvidos, e posteriormente, nos países subdesenvolvidos. Esse crescimento, ocorrido principalmente nos séculos XIX e XX tem levado a uma dicotomia da relação existente entre natureza e desenvolvimento urbano e industrial, no qual apenas na década de 1970, do século passado, foi que houve uma preocupação em discutir a nível mundial às questões ambientais, mediante ao alto grau de alteração sofrido por inúmeras áreas do planeta. Nesse contexto a zona costeira tem passado por uma intensa transformação em virtude do processo de 
valorização de seu território e crescimento tanto da atividade industrial, quanto da construção e ampliação de portos, por exemplo, como a atividade turística.

Com o passar das últimas décadas do século XX e início do século XXI, tem levado a uma mudança considerável na fisionomia da paisagem, bem como, dos aspectos sociais e até culturais de comunidades costeiras. Nesse contexto o município de São Gonçalo do Amarante se insere num ambiente costeiro com suas peculiaridades e importância do ponto de vista do uso dos recursos naturais. Em virtude das significativas mudanças ocorridas no litoral do município, principalmente devido a instalação do complexo portuário do Pecém, fez necessário um estudo que podesse identificar e correlacionar essas mudanças ocorridas tanto na praia do Pecém, onde está instalado o porto, quanto na praia da Taíba, localizada também no litoral do município. O objetivo deste trabalho baseou-se no estudo do processo de uso e ocupação ocorrido na área ao longo dos anos, bem como a influência dessa intervenção nas praias do Pecém e Taíba, localizadas no município de São Gonçalo do Amarante - CE. A área em alguns pontos tem apresentado uma considerável evolução do uso e ocupação dos processos erosivos, evidenciando a necessidade de estudos que possam dar base a esse contínuo processo, podendo assim identificar as intervenções e possíveis impactos ambientais.

Segundo dados da UNESCO (2003), cerca de $70 \%$ da população mundial residem nas áreas costeiras. No Brasil, essa faixa de terra concentra, aproximadamente, $25 \%$ da população do país, ou seja, cerca de 42 milhões de pessoas que estão diretas ou indiretamente relacionadas com o processo de intensa urbanização, atividades industriais e econômicas, bem como a atividade turística.

A Comissão Mundial sobre o Meio Ambiente e o Desenvolvimento, refere e explica em seu relatório de 1987 o termo de Desenvolvimento Sustentável, onde o mesmo atende às necessidades do presente sem comprometer a possibilidade de as futuras gerações satisfazerem suas próprias necessidades. O discurso da Comissão Mundial sobre o Meio Ambiente e Desenvolvimento (1991) enfatiza o desgaste do meio ambiente, onde o desenvolvimento sustentável deve-se constituir em um objetivo planetário.

A Resolução do Conselho Nacional do Meio Ambiente (CONAMA) Lei 01/1986 enfoca o impacto ambiental como "qualquer alteração das propriedades físicas, químicas e biológicas do meio ambiente, causadas por qualquer forma de matéria ou energia resultante das atividades humanas que, direta ou indiretamente, afetam a saúde, a segurança e o bem-estar da população; as atividades sociais e econômicas; a biota; as condições estéticas e sanitárias do meio ambiente e a qualidade dos recursos ambientais".

Tricart (1977) faz uma análise de um sistema, onde reconhece conceitualmente as partes interativas, tornando possível captar a rede interativa sem ter de separá-las e estabelece uma 
gradação entre a morfogênese, em que prevalecem os processos erosivos modificadores das formas de relevo, e a pedogênese, na qual prevalecem os processos formadores do solo considerando, ainda, as ações antrópicas como modificadoras das condições naturais dos ecossistemas (Quadro 1).

\begin{tabular}{|c|c|c|c|}
\hline $\begin{array}{l}\text { Ecodinâmica } \\
\text { dos ambientes }\end{array}$ & $\begin{array}{l}\text { Condições de balanço entre } \\
\text { morfogênese e pedogênese }\end{array}$ & $\begin{array}{l}\text { Vulnerabilidade } \\
\text { ambiental }\end{array}$ & Sustentabilidade ambiental \\
\hline $\begin{array}{l}\text { Ambientes } \\
\text { estáveis }\end{array}$ & $\begin{array}{l}\text { Possui uma estabilidade } \\
\text { pedogenética antiga em função da } \\
\text { fraca atividade do potencial } \\
\text { erosivo e também pela ação } \\
\text { antrópica onde o balanço entre os } \\
\text { processos morfogenéticos e } \\
\text { processos pedogenéticos é } \\
\text { francamente favorável à } \\
\text { pedogênese havendo um } \\
\text { equilíbrio entre os fatores do } \\
\text { potencial ecológico e fatores de } \\
\text { exploração biológica. }\end{array}$ & $\begin{array}{l}\text { Vulnerabilidade } \\
\text { nula ou muito } \\
\text { baixo: áreas com } \\
\text { características } \\
\text { relacionadas nos } \\
\text { setores de } \\
\text { sustentabilidade } \\
\text { alta. }\end{array}$ & $\begin{array}{l}\text { Sustentabilidade alta }- \text { áreas } \\
\text { dotadas de boa capacidade } \\
\text { produtiva dos recursos naturais e } \\
\text { com limitações que podem ser } \\
\text { mitigadas com aplicações de } \\
\text { tecnologias simples, onde as } \\
\text { características naturais estão } \\
\text { nitidamente em equilíbrio e bom } \\
\text { estado de conservação onde a } \\
\text { vulnerabilidade do ambiente é } \\
\text { baixa. }\end{array}$ \\
\hline $\begin{array}{l}\text { Ambientes de } \\
\text { transição }\end{array}$ & $\begin{array}{l}\text { A dinâmica do ambiente é } \\
\text { marcada pela preponderância de } \\
\text { processos morfogenéticos ou de } \\
\text { processos pedogenéticos, podendo } \\
\text { favorecer uma ou outra condição: } \\
\text { no caso de pedogênese, passa-se } \\
\text { aos meios estáveis; no caso de } \\
\text { morfogênese, passa-se aos meios } \\
\text { instáveis. }\end{array}$ & $\begin{array}{l}\text { Vulnerabilidade } \\
\text { moderada - áreas } \\
\text { que apresentam } \\
\text { características } \\
\text { contidas nos } \\
\text { ambientes com } \\
\text { sustentabilidade } \\
\text { moderada. }\end{array}$ & $\begin{array}{l}\text { Sustentabilidade moderada - } \\
\text { áreas com razoável capacidade } \\
\text { produtiva dos recursos naturais, } \\
\text { em que se incluem condições } \\
\text { satisfatórias desses recursos, nestas } \\
\text { áreas ocorrem vulnerabilidades } \\
\text { moderadas. }\end{array}$ \\
\hline $\begin{array}{l}\text { Ambientes } \\
\text { instáveis }\end{array}$ & $\begin{array}{l}\text { Nota-se a degradação ambiental } \\
\text { evidente, neste caso predomina a } \\
\text { morfogênese com aspectos do } \\
\text { meio ambiente bastante } \\
\text { degradado. }\end{array}$ & $\begin{array}{l}\text { Vulnerabilidade } \\
\text { alta ou muito forte } \\
\text { - áreas com } \\
\text { condições de } \\
\text { sustentabilidade } \\
\text { enquadradas nas } \\
\text { categorias de } \\
\text { sustentabilidade } \\
\text { baixa ou muito } \\
\text { baixa. }\end{array}$ & $\begin{array}{l}\text { Sustentabilidade baixa - áreas } \\
\text { com séries problemas quanto à } \\
\text { capacidade produtiva dos recursos } \\
\text { naturais renováveis onde se nota a } \\
\text { degradação ambiental ainda em } \\
\text { grandes proporções, causando o } \\
\text { desequilíbrio dos ecossistemas, } \\
\text { caracterizando-se nestes } \\
\text { ambientes, vulnerabilidade alta. }\end{array}$ \\
\hline
\end{tabular}

Quadro 01. Classificação da ecodinâmica do ambiente. Fonte: Adaptado de Tricart (1977) e Santos e Souza (2006).

Bertrand (1972) explicita em seu trabalho as relações entre paisagem e o geossistema, no qual define geossistema como um complexo dinâmico que resulta da combinação do potencial ecológico (fatores geomorfológico, climático e hidrológico) e a exploração biológica (vegetação, solo e fauna) que deve apresentar um mesmo tipo de evolução morfogenética e a mesma degradação antrópica.

A cartografia temática é um instrumento que tem contribuído para o sensoriamento remoto e geoprocessamento. Carvalho (2000) enfatiza o princípio básico que possibilita a obtenção de informações sobre o levantamento dos recursos naturais renováveis por meio da tecnologia de 
sensoriamento remoto, que consiste no comportamento espectral dos alvos terrestre, que é registrado por um sistema sensor. Destaca ainda, o posicionamento relativo dos dados e/ou informações, estudando como representar as mais variadas classes temáticas, graficamente, de modo claro, prático e objetivo.

Zuquete (2004) demonstra como podem ser elaborados os documentos cartográficos, principalmente as cartas de declividade e as de caracterização das feições de relevo. Casseti (1991) chama atenção em seu trabalho para o significado do relevo, sobretudo como suporte das derivações ambientais observadas durante o processo de apropriação e transformação realizado pelo homem. Neste trabalho, Casseti demonstra a relação dialética da natureza com o homem, evidenciando que essa relação se encontra vinculada ás relações entre os próprios homens.

O Estado do Ceará, tem se destacado no cenário nacional e internacional pela sua inserção na atividade turística, que tem como elemento principal de divulgação, as belezas paisagísticas advindas da região litorânea. Com o crescente ritmo do uso e ocupação da zona costeira, veio a consequente mudança e evolução espaço-temporal de várias áreas. Alguns estudos relacionam essa temática com as áreas de mudanças na paisagem dos ambientes costeiros, como por exemplo, Meireles et al. (1999), Moura (2012), destacando os aspectos de vulnerabilidade e erosão das áreas costeiras dos municípios de Caucaia e Aquiraz, Freire (et al., 2006), Souza (2000) na compartimentação da zona costeira do Ceará, Muehe (1998), Pinheiro (2003), Morais (2000) e Cavalcanti (2003) ainda sobre os processos de erosão nas áreas costeiras.

A área em estudo (Figura 1) está localizada na costa Oeste do Estado, compreendendo todo o litoral do município de São Gonçalo do Amarante, Ceará. Na área de estudo identificou-se a presença de campos de dunas e lagoas costeiras que são atributos de grande importância para o meio ambiente da região, onde a mesma vem apresentando nos últimos anos um forte potencial de desenvolvimento o que por consequência ocasiona um crescimento considerável no processo de uso e ocupação, cujo objetivo da Pesquisa foi analisar os principais impactos ambientais e verificar o crescimento urbano dessa área, contatando os usos da mesma.

O litoral do município conta com aproximadamente $25 \mathrm{~km}$ de litoral no qual abrange as praias do Pecém, onde está situado o Porto, praia da Colônia e a praia da Taíba. Essas áreas possuem grande beleza paisagística e posição estratégica para a economia do Estado do Ceará, tendo em vista a presença do Porto do Pecém e da atividade turística, antes mencionada. No entanto seu litoral já sofre uma transformação em virtude de seu uso e ocupação, trazendo-lhe impactos ambientais, como por exemplo, de acordo com Dias e Barreiras (2011), a incidência de aspectos erosivos na praia da Taíba, por exemplo. 


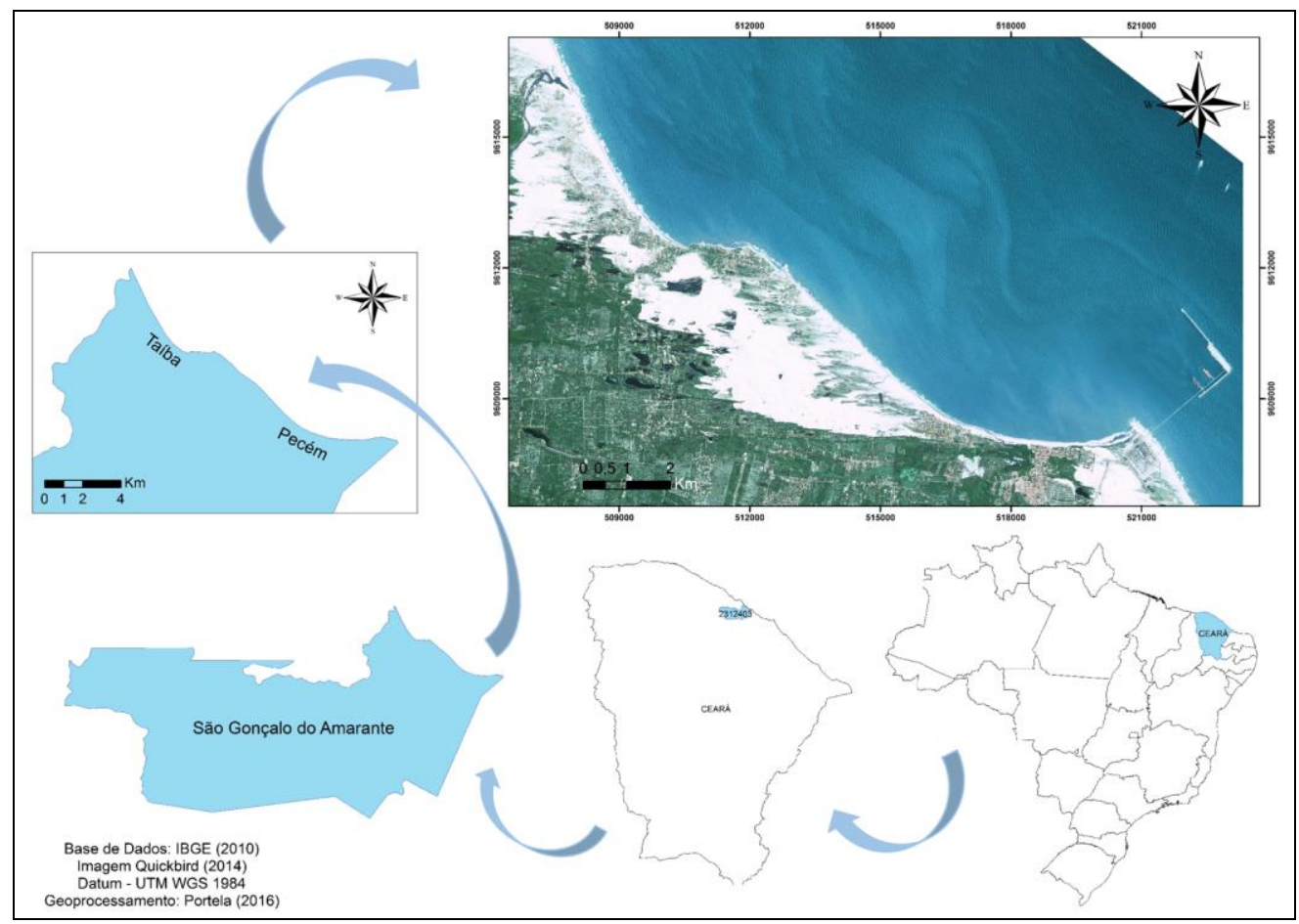

Figura 1. Localiação da área - Praias do Pecém e Taíba, São Gonçalo do Amarante, Ceará. Fonte: Portela (2016).

\section{METODOLOGIA}

\subsection{Base de dados bibliográficos e geocartográficos}

Primeiramente foram realizadas pesquisas bibliográficas e cartográficas referentes à temática proposta, sendo para isso, consultadas diversas instituições como Instituo de Pesquisa e Estratégia Econômica do Ceará (IPECE), Superintendência Estadual do Meio Ambiente (SEMACE), Universidade Federal do Ceará (UFC), Serviço Geológico do Brasil (CPRM), Instituto do Desenvolvimento Agrário do Ceará (IDACE), Instituto Brasileiro do Meio Ambiente e dos Recursos Naturais Renováveis (IBAMA), dentre outros órgãos.

Foram realizados trabalhos de campo entre os anos de 2014 a 2017, objetivando a obtenção de registros fotográficos e observações, no tocante as modificações impostas pelo homem. Posteriormente foi realizado a análise multitemporal através de registros fotográficos, sendo verificado o grau de mudança na paisagem, principalmente das estruturas implantadas no ambiente costeiro das praias do Pecém e Taíba no município de São Gonçalo do Amarante, sendo analisado a relação existente entre o processo de uso e ocupação com os impactos ambientais. Para uma melhor interpretação das análises, a área foi setorizada em dois setores, de acordo com a Figura 2. 


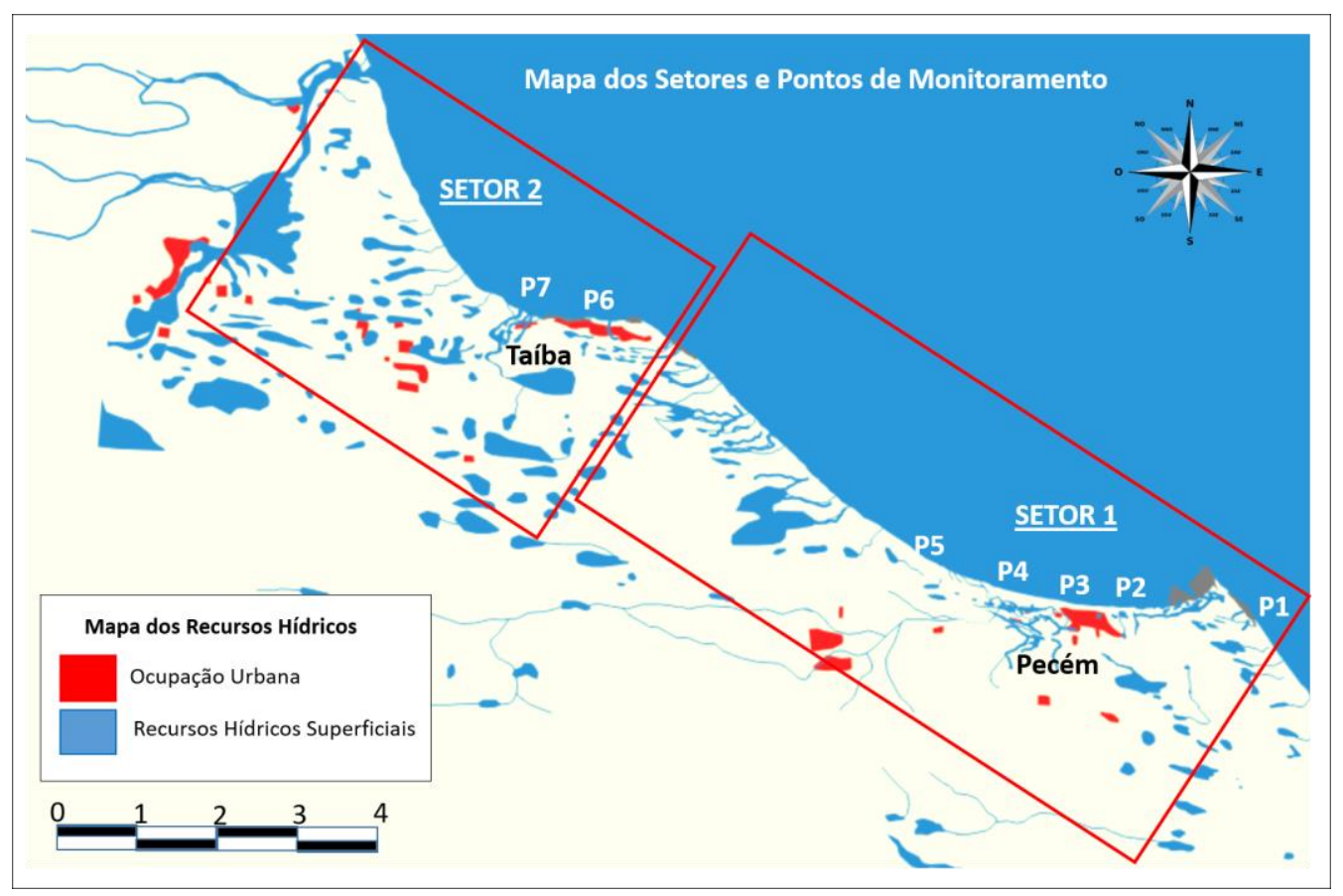

Figura 2. Compartimentação da área de pesquisa em dois setores. Fonte: Portela (2016).

Através do estudo geossistêmico buscou-se uma maior compreensão do ambiente estudado, tendo em vista que a natureza dessa análise sugere uma conexão entre os elementos do ambiente local, conjugando o potencial ecológico, que sofre interferências da ação antrópica, na qual, segundo Cristofoletti (1979), essa análise tende a tornar o estudo mais consistente do ponto de vista da análise ambiental.

Utilizou-se para esta pesquisa técnicas e ferramentas geoprocessamento, que segundo Dias et al. (2013) citado por Moraes e Lima (2015) é uma ferramenta poderosa e precisa, na qual permite realizar investigações e oferecer produtos digitais básicos e aplicados para as análises de cada situação. As etapas desta pesquisa se deram de acordo com a Figura 3, que inicialmente foram feitos levantamentos bibliográficos e geocartográficos da região litorânea de São Gonçalo do Amarante, correspondente às praias do Pecém e da Taíba.

Os materiais geocartográficos constaram de imagens de satélites multitemporais (Quickbird (2004; 2014)) e o mosaico de fotografias aéreas de 1965. As etapas de campo foram realizadas nos meses de abril e outubro dos anos de 2013 a 2016, para registros fotográficos e observação dos impactos ambientais ao longo da pesquisa. A etapa de geoprocessamento constou de tabular os dados em ambiente dos Sistemas de Informações Geográficas (SIGs), no qual foi utilizado software como o ArcGIS 10.3 do Laboratório de Geologia Marinha e Aplicada da Universidade Federal do Ceará. Essa tabulação fora organizada no sistema UTM WGS1984S, sendo possível identificar as feições naturais e antropogênicas, bem como a delimitação das unidades Geossistêmicas e a relação do uso e ocupação dessa área. 


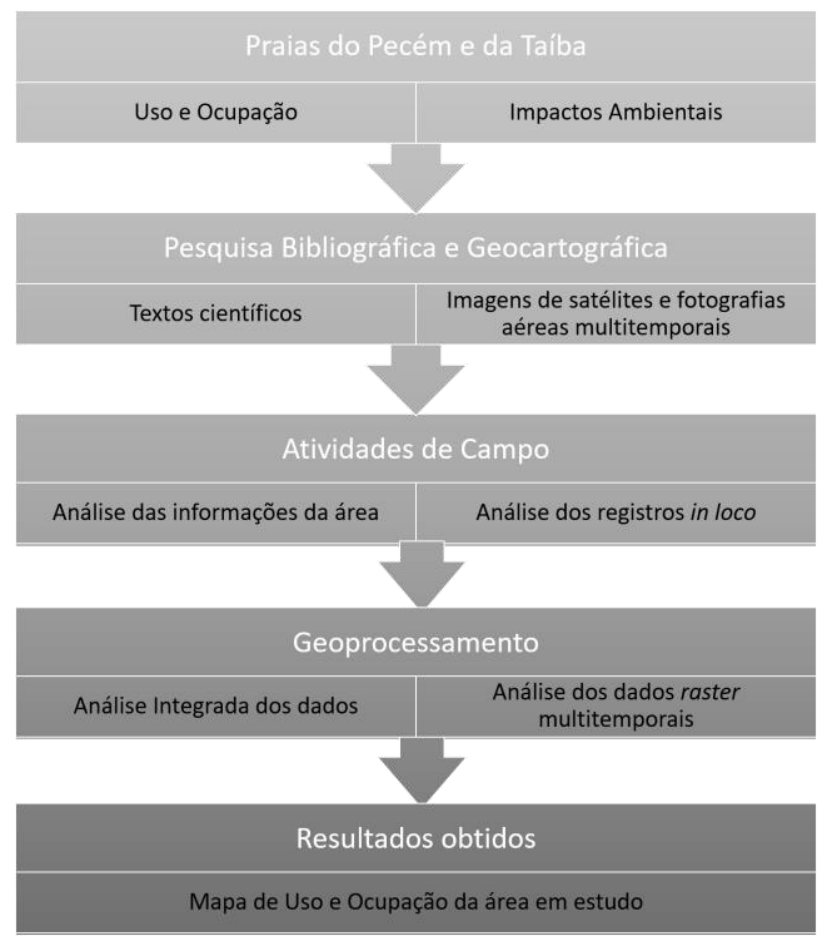

Figura 3. Fluxograma do percurso metodológico. Fonte: Elaborado pelos autores.

\section{RESULTADOS E DISCUSSÃO}

Na análise ambiental das Praias do Pecém e Taíba do município de São Gonçalo do Amarante- Ceará, destacou-se principalmente os impactos ambientais diretos na região litorânea principalmente logo após a instalação do Complexo Portuário do Pecém. Percebeu-se também, que houve o progresso da ocupação de dunas da região do Pecém e Taíba, processos erosivos na região praial, além da crescente atividade turística e de cunho econômico, como a implantação de geradores eólicos.

\subsection{PRAIA DO PECÉM}

A Praia do Pecém (Figura 4) é uma Vila de Pescadores localizada no município de São Gonçalo do Amarante-CE. Esta região no passado foi habitada pelos Índios Anacé, Guanacés e Jaguaruanas (ainda hoje existem remanescentes desses indígenas).

Esta Praia está entre as praias de Cumbuco e Paracuru, a $60 \mathrm{~km}$ de Fortaleza, o acesso pode ser feito pela Rodovia do Sol Poente. Por sua localização privilegiada, foi escolhida para sediar o novo Porto cearense que, juntamente com o Porto de Fortaleza, no Mucuripe, escoa a produção industrial do Ceará. Com a construção do Complexo Industrial e Portuário do Pecém esta área da praia foi diminuída o que trouxe prejuízos à vila de pescadores do Pecém e consequentemente ao 
turismo da região (CEARÁ, 2017).

\subsubsection{Porto do Pecém}

O Porto do Pecém é um dos terminais portuários da Costa do Nordeste mais importantes localizado no município de São Gonçalo do Amarante, Ceará, estilo "Off Shore" construído sob um acidente geográfico denominado "Ponta do Pecém", situado na praia do Pecém, litoral oeste do Ceará, faz parte da Região Metropolitana de Fortaleza (RMF) a cerca de $60 \mathrm{~km}$ da capital do estado, Fortaleza. Para navegação através da Carta Náutica n 705 , de 28/09/2002, elaborada pela Diretoria de Hidrografia e Navegação (DHN), da Marinha do Brasil (MB) (CEARÁ PORTOS, 2017) (Figura 4 A e B).

A condição geográfica de Pecém, "com o menor tempo de trânsito entre o Brasil, os Estados Unidos e a Europa, média de 7 dias para chegar ao destino, funciona como um dos atrativos para conquistar os armadores e impulsionar as exportações brasileiras” (CEARÁ PORTOS, 2017).
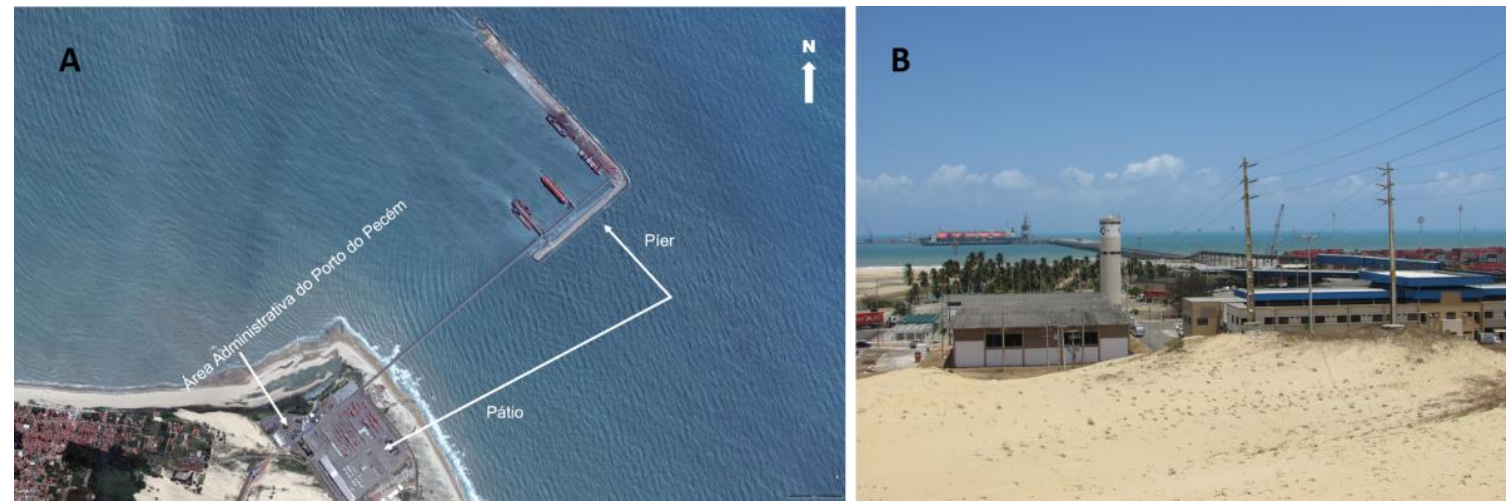

Figura 4. A) Imagem de satélite mostrando o Terminal Portuário do Pecém; B) Imagem de satélite mostrando o Terminal Portuário do Pecém. Fonte: Google Earth (2016). Org. Portela (2017).

\subsubsection{Histórico do Porto do Pecém}

Na década de 1990 as limitações do Porto do Mucuripe, em Fortaleza, fizeram com que os governantes do Ceará, buscassem uma alternativa para o recebimento de cargas e mercadorias pelo mar. Era um período onde nascia o desenvolvimento do estado e o Porto de Fortaleza ficava não mais atendia as necessidades de importação e exportação local. Dentre os empreendedores da capital cearense, levaram as necessidades do estado ao Governo Federal com o objetivo de angariar fundos, com a proposta de construção de um novo porto (CEARÁ PORTOS, 2017).

A análise que foi feita era que o Porto do Mucuripe não tinha condições de ampliação, daí iniciaram estudos para encontrar um novo local, para um novo porto. Surgiu então duas 
possibilidades de localização desse empreendimento, o litoral de Paracuru ou São Gonçalo do Amarante, tanto pela proximidade de Fortaleza, como também das condições físicas geográficas locais (CEARÁ PORTOS, 2017). Na Figura 5 observa-se a progressiva mudança da ponta do Pecém, feição geológica que foi alterada ao longo dos anos de implementação do Porto do Pecém, bem como da sua ampliação ocorrida nos últimos anos.

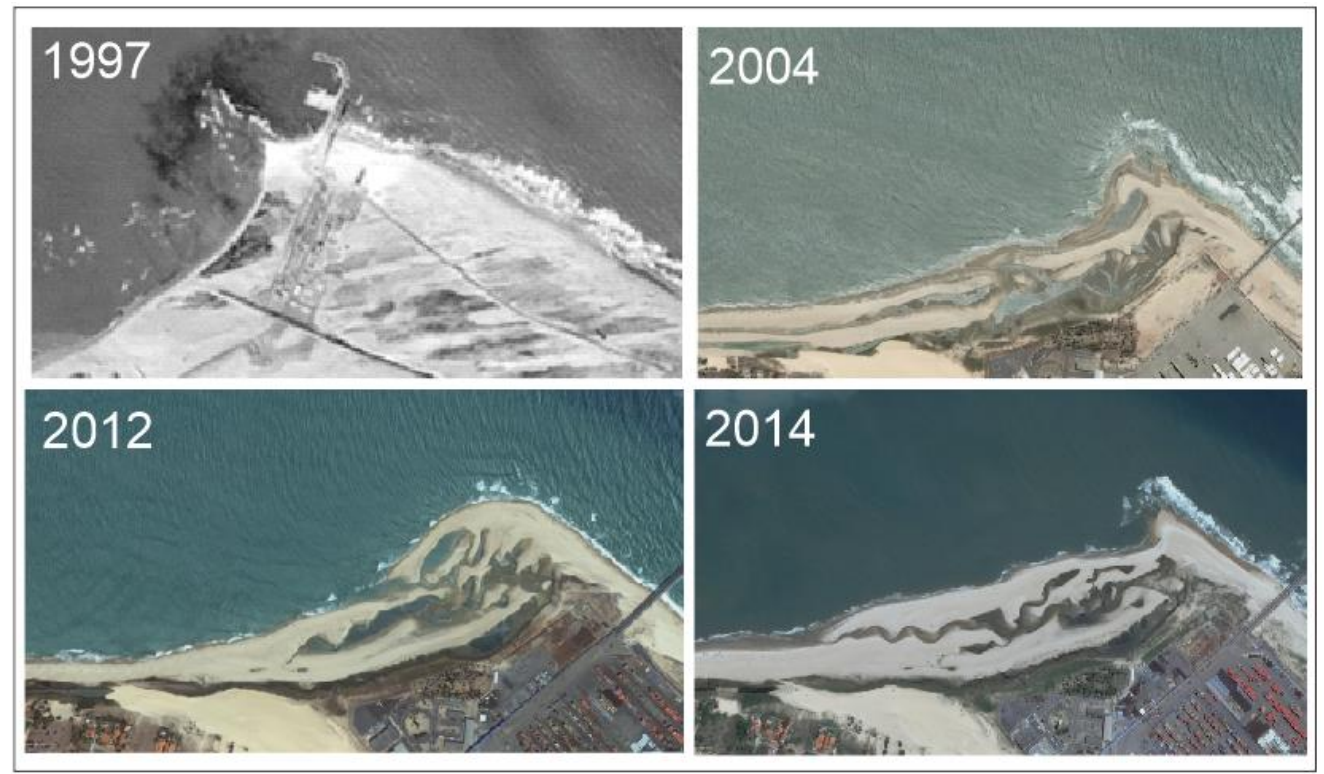

Figura 5. Imagens multitemporais de satélite da Ponta do Pecém, início da obra do Terminal Portuário do Pecém, até as configurações atuais. Fonte: Magini et al. (2013).

Ao certo, São Gonçalo do Amarante e Paracuru tinham as condições ideais para o recebimento da estrutura, por possuir geograficamente denominado de Ponta do Pecém em São Gonçalo do Amarante a mais adequada, "pois oferecia um abrigo natural e uma enseada com profundidade suficiente para a construção". Naquele momento estava se materializando um dos maiores projetos de desenvolvimento econômico já implementados no Ceará, o Complexo Industrial e Portuário do Pecém (CEARÁ PORTOS, 2017).

Há exatos 20 anos a história do Porto do Pecém começava a ser escrita. Foi no dia 22 de dezembro de 1995 que o decreto da Assembleia Legislativa do Ceará, sancionado pela Lei n. ${ }^{\circ}$ 12.536/95, criava a Companhia de Integração Portuária do Ceará (CEARÁ PORTOS), vinculada à Secretaria de Infraestrutura do Estado (SEINFRA), que seria a responsável pela administração do Terminal Portuário do Pecém e por promover o desenvolvimento econômico do Estado do Ceará (CEARÁ, 2017).

O Porto do Pecém entrou em operação em 2002. Na primeira fase, houve a movimentação de granéis líquidos, trazidos pela PETROBRÁS. Com a ausência da siderúrgica, foi aprovada a 
operação de cargas gerais no berço de granéis sólidos, que traria carvão e minério de ferro para a siderúrgica e devolveria aos navios placas de aço (CEARÁ PORTOS, 2017).

Caracterização das Unidades de Conservação no Brasil e Ceará

Com o objetivo de diminuir o alto grau de degradação ambiental das diversas áreas afetadas por esse processo urbano-industrial, foram estabelecidas as Unidades de Conservação (UC), no qual os Estados Unidos se configuram como os pioneiros ao criar, em 1872, o Parque Nacional Yellowstone no estado de Wyoming. Diegues (1996) destaca a criação das "ilhas" de conservação ambiental proposta pelos conservacionistas americanos com o objetivo de fazer com que o homem da cidade pudesse apreciar e reverenciar essa natureza selvagem.

A década de 1930 marcou de certa forma para o Brasil o início da política ambiental, no qual podemos destacar a criação do primeiro código florestal, estabelecido pelo Decreto 23.793 de 23 de janeiro de 1934, e do código das águas pelo Decreto $\mathrm{n}^{\circ} 24.643$ de 10 de junho do mesmo ano. Posteriormente, em 1937 houve a criação da primeira Unidade de Conservação no estado do Rio de Janeiro, o Parque Nacional de Itatiaia, criação esta que foi estabelecida pelo artigo $9^{\circ}$ do Código Florestal de 1934 (PORTELA, 2009). Em 2000, foi criada a Lei 9.985 de 18 de julho de 2000 que institui o Sistema Nacional de Unidades de Conservação da Natureza, que dentre os seus objetivos estão o de contribuir para a preservação e a restauração da diversidade dos ecossistemas naturais e promover o desenvolvimento sustentável a partir destes recursos.

No âmbito estadual, a preocupação relacionada às questões ambientais, levou o governo a criar em 1987 o Conselho Estadual do Meio Ambiente e a Superintendência Estadual do Meio Ambiente (SEMACE), com objetivos de executar a política ambiental a fim de promover a sustentabilidade ambiental em consórcio com o desenvolvimento do estado do Ceará. A Educação Ambiental também foi colocada como pressuposto fundamental para essa proteção do meio ambiente, na qual, podemos verificar a adoção dos programas de Educação Ambiental na política estadual, como por exemplo, a criação do Programa de Educação Ambiental do Ceará (PEACE) criado em 1995 (CEARÁ, 2003).

No decorrer das últimas décadas os governos, em geral, têm criado várias Unidades de Conservação sendo a proteção e conservação da biodiversidade o enfoque principal. Em 1985, segundo dados do IBAMA, apenas 1,49\% do território brasileiro era ocupado por essas unidades de conservação. As perdas e ameaças à diversidade biológica têm gerado muita preocupação entre os conservacionistas, que vem reivindicando e obtendo avanços na legislação ambiental tanto em nível federal, estadual e até municipal (ROCHA, 2004).

Avanços aconteceram e nos últimos anos, houve um aumento resultando em quase 1,5 milhões de $\mathrm{km}^{2}$, ou 16,6\% do território continental brasileiro e 1,5\% do território marinho, 
destinados para a conservação da biodiversidade, preservação de paisagens naturais com notável beleza cênica, uso sustentável dos recursos naturais e valorização da diversidade cultural brasileira (BRASIL, 2012).

Um marco importante para este aumento foi a criação, em 2000, da lei que estabelece o Sistema Nacional de Unidades de Conservação (SNUC), no qual se refere às questões relacionadas à utilização, implantação e gestão dessas unidades. Essa lei no 9.985, de 18 de julho de 2000 regulamenta o artigo 225 parágrafos $1^{\circ}$, incisos I, II, III e VII da Constituição Federal de 1988. Dentre as categorias de Unidades, a lei estabelece duas: as de uso direto ou sustentável e as de uso indireto ou de proteção integral (BRASIL, 2000).

A criação de APAs no Brasil foi estabelecida com base nos modelos europeus, como por exemplo às chamadas "Landschaftsschutzgebiet" (área de conservação da Alemanha), na qual eram estabelecidas para a proteção da natureza e recomposição do equilíbrio natural (BRITO e CÂMARA, 1998). Com base nisso, verifica-se que as APAs criadas no Brasil, tinham além do caráter de proteção e preservação relativa a manutenção do equilíbrio ambiental, uma preocupação em promover também uma melhoria na qualidade de vida das populações, juntamente com a promoção do desenvolvimento social, o que possibilitaria o alcance na sustentabilidade social e ambiental.

O estado do Ceará possui diversas potencialidades ambientais que se traduzem em áreas de relevante interesse ecológico, que se exprime à necessidade de uso e manejo sustentável dessas áreas, daí a necessidade de se implantar diversas unidades de conservação. No Ceará as unidades de conservação estão distribuídas entre os diversos ecossistemas existentes no estado e sob a administração de órgãos como IBAMA, a SEMACE e as Secretarias Municipais de Meio Ambiente. Verifica-se que as APAs estão em maior número no estado do Ceará, ocupando cerca de 42,3\% do total de Unidades de Conservação existente no estado, seguido das reservas particulares do patrimônio natural, que abrange aproximadamente $17 \%$ do total existente.

\subsubsection{Unidades de Conservação na região da Praia do Pecém}

Na região da Praia do Pecém foram criadas duas Unidades de Conservação (UC) em virtude da implementação do Porto do Pecém, a Área de Preservação Ambiental do Pecém e a Estação Ecológica do Pecém, conforme o Plano Diretor do Complexo Industrial e Portuário do Pecém.

A Área de Preservação Ambiental do Pecém não está contemplada na área da presente pesquisa, portanto, será aborda apenas sobre a Estação Ecológica do Pecém. A parte da estação que fica em São Gonçalo do Amarante (na área da pesquisa) está totalmente situada no distrito do 
Pecém. Figura 8 observa-se a presença de residentes, ou seja, a desapropriação não foi concluída na área da estação ecológica.

A Estação Ecológica do Pecém é uma Unidade de Conservação Estadual administrada pela SEMACE, apresenta uma área total de 973,09 hectares e está localizada nas áreas municípios de São Gonçalo do Amarante e Caucaia. Uma de Unidade Conservação pertencente à categoria "Estação Ecológica" tem como objetivo a preservação da natureza e a realização de pesquisas científicas (SNUC, art. $9^{\circ}$ ). Nas Estações Ecológicas são proibidas certas atividades como: visitação pública é proibida, exceto quando há objetivo pesquisas científicas (de acordo com o que dispuser o Plano de Manejo da unidade ou regulamento específico), segundo a lei do (SNUC, art. $9^{\circ}$ ) (SEMACE, 2017).

Além disso, de acordo com o Decreto no 4.340/2002 (art. 27), "o uso de imagens de unidade de conservação com finalidade comercial deve ser cobrado conforme estabelecido em ato administrativo pelo órgão executor". Quando a finalidade do uso de imagem da unidade de conservação for preponderantemente científica, educativa ou cultural, o uso está permitido deste que autorizado pelo órgão competente (SEMACE, 2017).

\footnotetext{
Revisão de Plano de Manejo; Reestruturação e criação do Conselho Gestor; Realização de seminários sobre legislação ambiental para a comunidade local; Registro de projetos e iniciativas ambientais; Instalação de escritório/sede da unidade (Centro de Promoção Turístico-Ambiental / CPTA); Implantação de projeto de sinalização da UC; Recuperação de áreas degradadas; Plano de gestão participativo; Estímulo ao ecoturismo sustentável; Programa de educação ambiental-peace para área; Estímulo à coleta seletiva de resíduos sólidos; Fiscalização de construção, reforma e ampliação de empreendimentos em áreas do litoral oeste, visando a regularização.
}

A Estação Ecológica do Pecém (Figura 6) apresenta como principal objetivo proporcionar o equilíbrio ecológico do ecossistema de dunas, móveis e edafisadas, que compõem as áreas próximas à construção do Complexo Portuário Industrial do Pecém (CIPP) (SEMACE, 2017). 

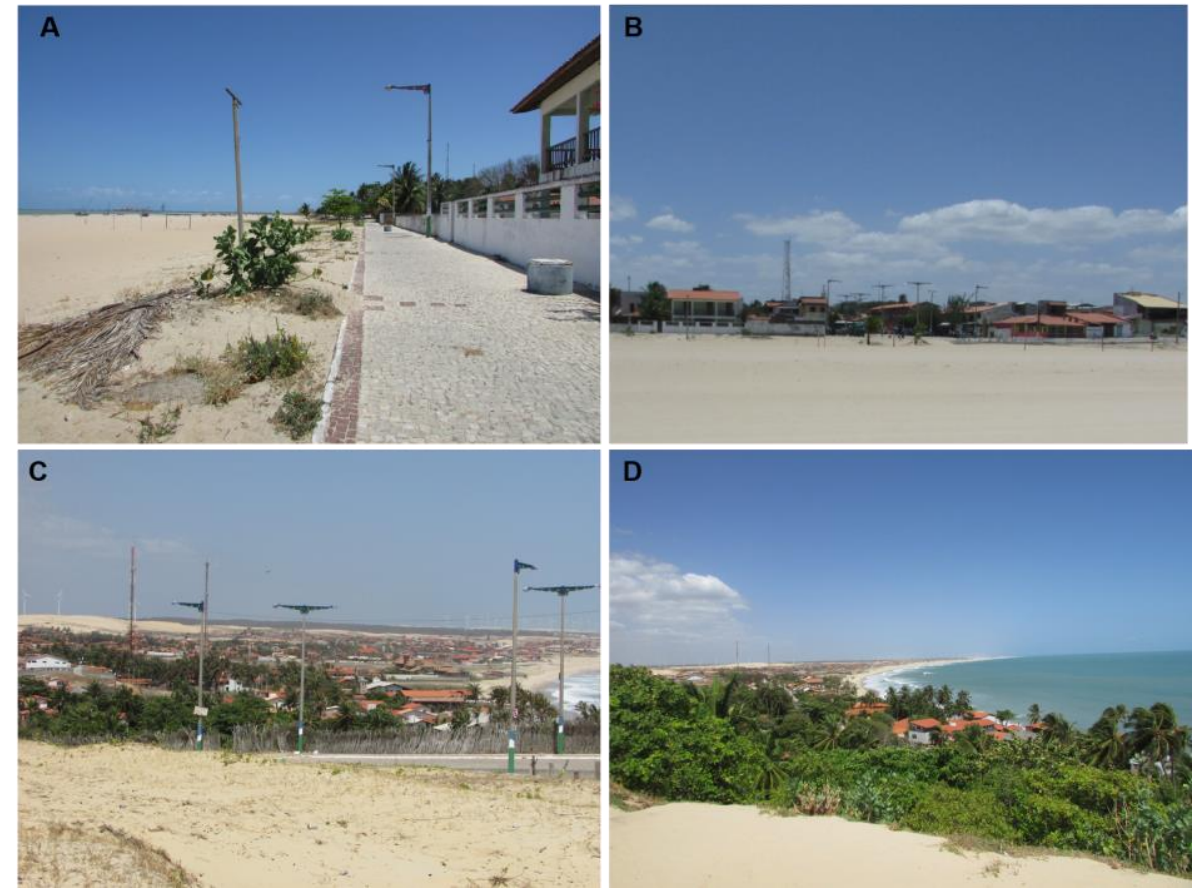

Figura 6. Mosaico de fotografias da Praia do Pecém, na área da Estação Ecológica. Fonte: Portela (2017). Legenda: Todas s imagens correspondem ocupação da Praia do Pecém, na área correspondente a Estação Ecológica.

\subsection{URBANIZAÇÃO}

\subsubsection{Urbanização nas áreas da Praia do Pecém e Taíba}

Para que haja um planejamento e monitoramento dessa zona costeira faz-se necessário o conhecimento das zonas de maior tendência a riscos costeiros. Morais (1996) afirma que o impacto ambiental nas zonas costeiras é bastante considerável, pois é onde tende a se concentrar a maior parte da população, ocasionando certa instabilidade do ambiente se este não for utilizado com um planejamento ambiental adequado.

A preocupação em regulamentar o uso e ocupação dessa zona costeira está expressa na Lei Federal $\mathrm{N}^{\circ} 7.661$ de 16 de maio de 1988, em que institui o Plano Nacional de Gerenciamento Costeiro (PNGC), que foi coordenado pelo Ministério do Meio Ambiente, Recursos Hídricos e Amazônia Legal (SOUZA, 2004).

Com base nos objetivos citados, podemos considerar que o gerenciamento perpassa não só a escala do monitoramento e zoneamento, mas também a participação da comunidade nesse processo de planejamento e "fiscalização". Vasconcelos (2005) destaca que: "o poder público não incorporou em sua metodologia de trabalho a consulta às populações locais que, verdadeiramente, deveriam ser os maiores interessados nas ações que são previstas para a zona costeira...”. 
A área apresentou nas últimas décadas, uma evolução urbana intensa na escala temporal de 1965 a 2014 e consequente transformação da paisagem local. Essa modificação se deu em virtude, principalmente, da atividade turística que exige os equipamentos que lhes dão suporte como pousadas, hotéis, dentre outros. Na comparação feita entre os registros fotográficos de épocas diferentes, é notória a parcela de descaracterização do ambiente natural da praia para um ambiente bastante modificado pelas ações antrópicas.

O setor 1 está representado pela praia da Pecém, se encontra maior adensamento urbano, configurando-se como a área de maior uso e ocupação estabelecidos nesse trabalho (figura 7). A maior quantidade de equipamentos converge para a atividade turística como: barracas, hotéis, pousadas, casas de veraneio etc. Também se observou uma grande concentração de estruturas na faixa de praia como barracas, pousadas bares e restaurantes.
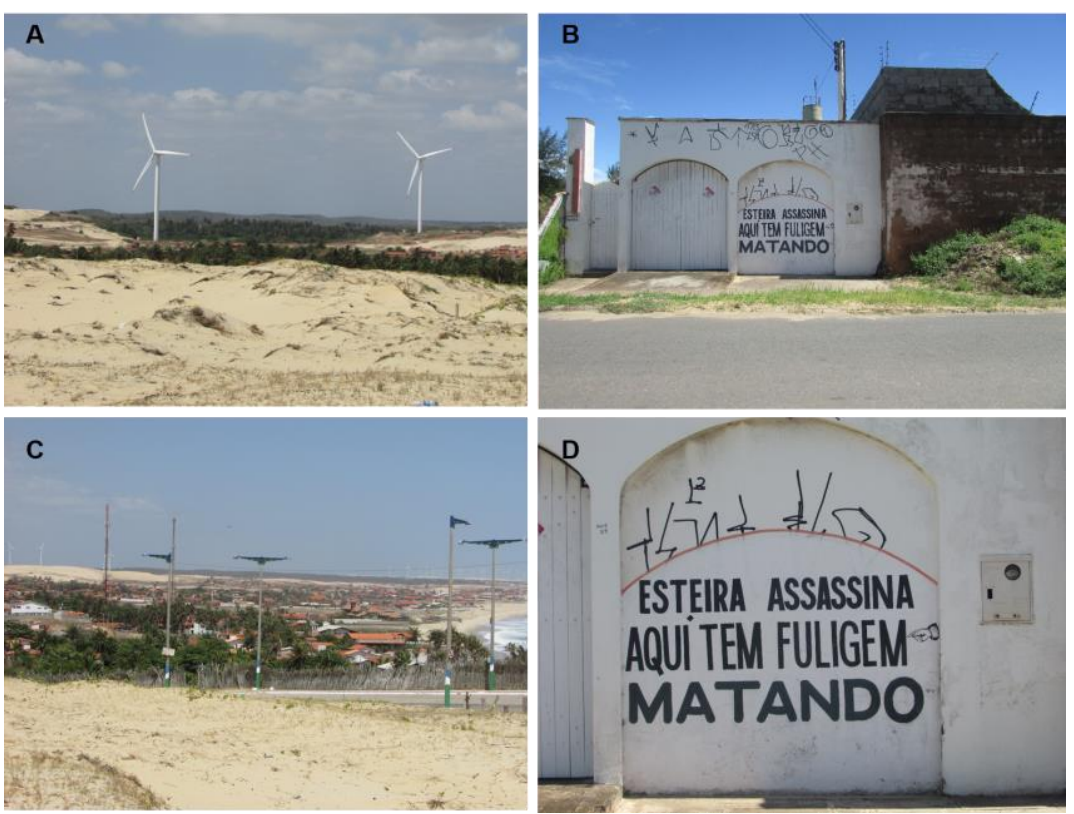

Figura 7. Impactos ambientais das praias do Pecém e Taíba (1995 - 2014). Fonte: Portela (2017). Legenda: A e C) Energia eólica próximo a ocupações urbanas, nas proximidades da Estação Eólica; E e D) Manifestação da população pela poluição causado pelo uso da esteira do Porto do Pecém.

O setor 2 está representado pela praia da Taíba, é caracterizada por certa estabilidade devida ao baixo percentual de ocupação, no qual apresentou a quase inexistência de equipamentos urbanos e uma pequena concentração de banhistas na área. Nesse setor foi observada a presença de rochas de praia dispostas no estirâncio superior, caracterizando-se como um ambiente relativamente estável com o baixo nível de uso e ocupação.

Ainda na porção Oeste do litoral do município, observa-se empreendimentos turísticos de importância bastante significativa, principalmente no que se refere a especulação imobiliária visando o desenvolvimento turístico da área. Foi verificado nas duas praias estudadas, Pecém e 
Taíba, projetos de empreendimentos voltados para a expansão de moradias, sendo que foram observadas construções em áreas não permitidas por lei, vindo a sofrer a ação dos processos da morfodinâmica litorânea, como pode ser observado na Figura 8.
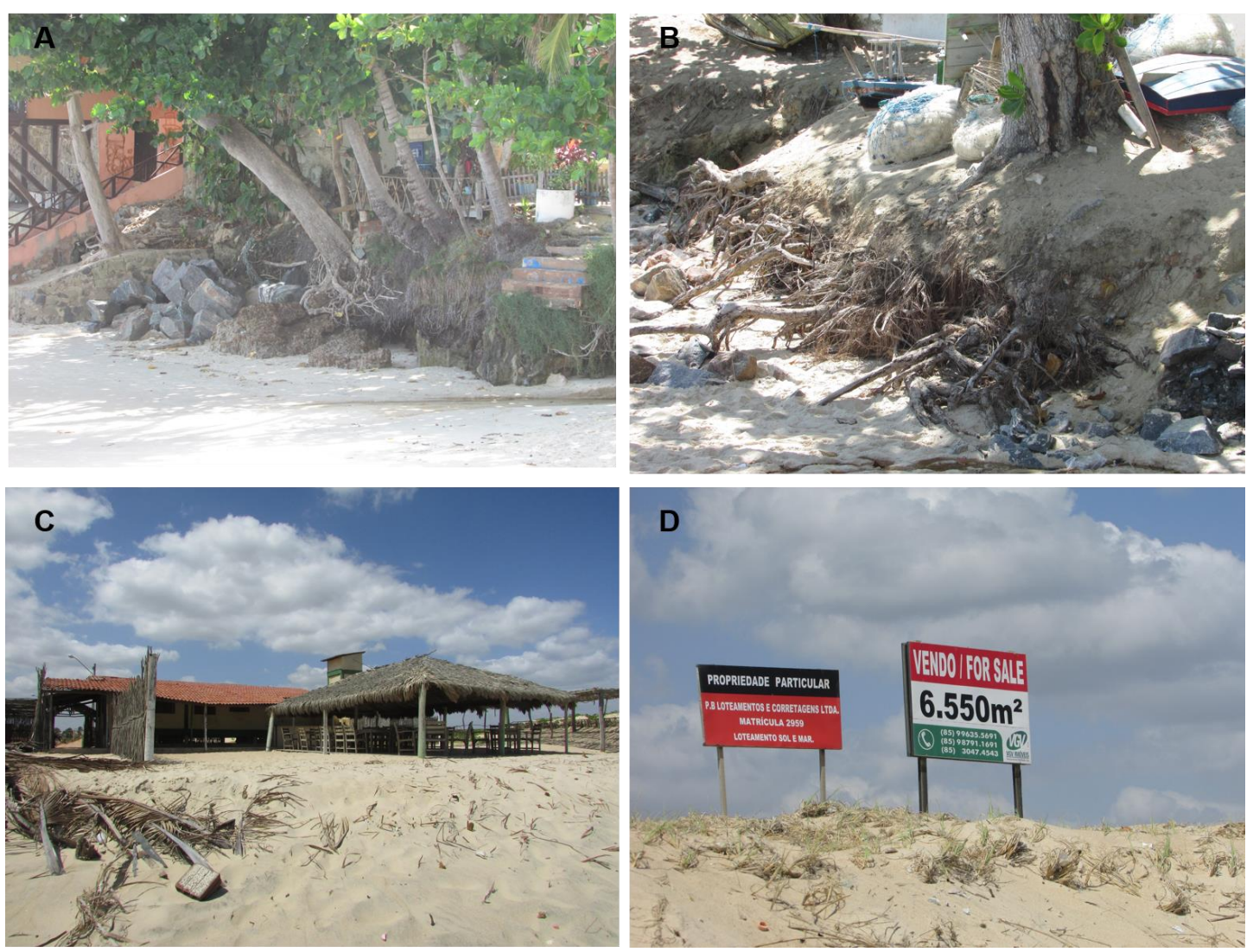

Figura 8. A) Identificação dos impactos ambientais nas praias do Pecém e Taíba (1995 - 2014). Fonte: Portela (2017). Legenda: A; B e C) Especulação imobiliária em zona de berma; e D) Venda de terrenos em áreas de dunas, áreas de preservação por lei.

Para que fosse possível fazer uma análise do uso e ocupação das praias do Pecém e Taíba, foram estabelecidas análises em uma escala temporal de 1965 e 2014, níveis de intensidade relacionados ao uso e ocupação da área, sendo para isso feita uma compartimentação da praia em dois setores de monitoramento. Cada setor representa um determinado grau de uso e ocupação (Figura 9).

Porém, para que se tenha um real desenvolvimento socioambiental, faz-se necessário não só a instalação e implementação dos projetos hoteleiros, mas também seriedade de políticas públicas que desenvolva um projeto paralelo de capacitação e desenvolvimento da mão-de-obra local, cabendo principalmente ao poder público, a inserção dessa população no desenvolvimento da atividade turística da região. O que não se observa no caso do projeto hoteleiro das praias do Pecém e Taíba. 

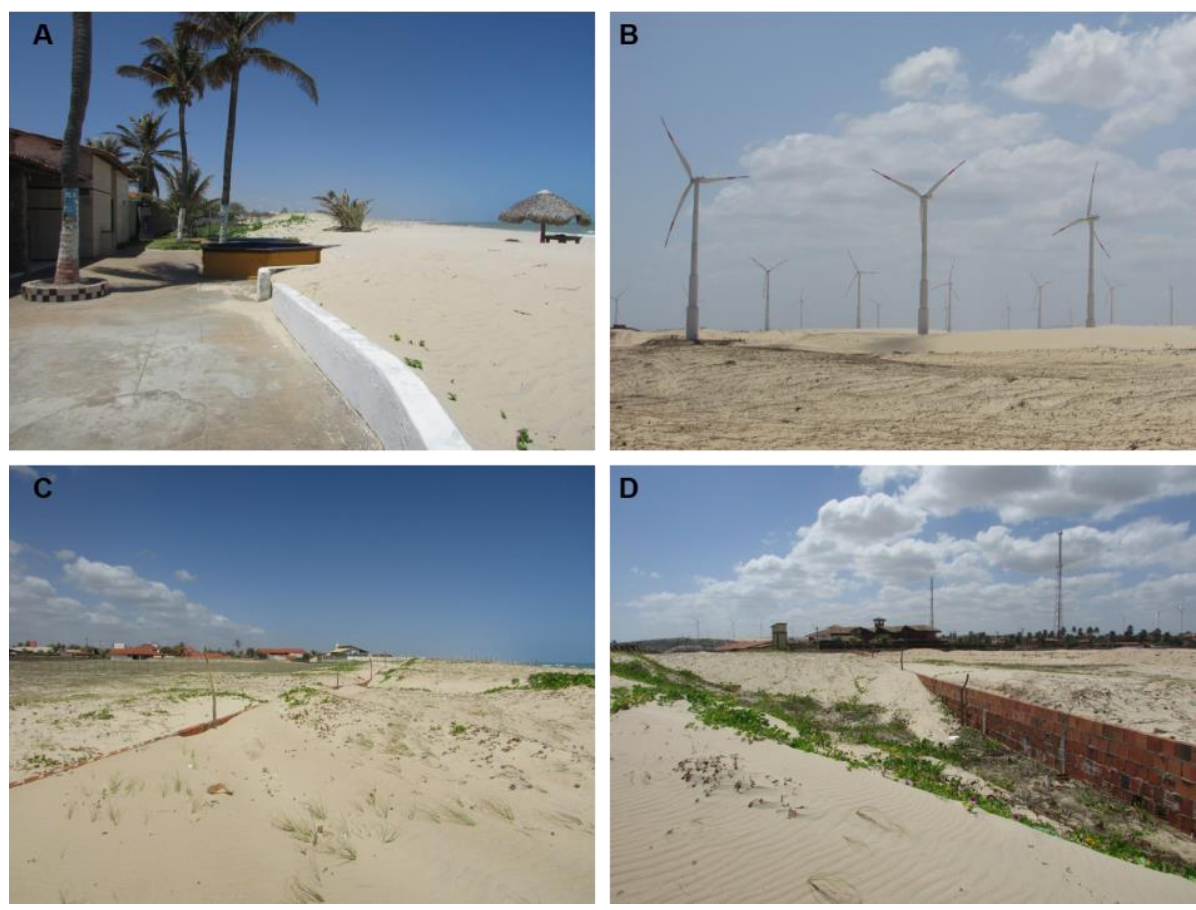

Figura 9. A) Identificação dos impactos ambientais nas praias do Pecém e Taíba. Fonte: Portela (2017). Legenda: A) Identificação dos impactos ambientais nas praias do Pecém e Taíba (1995 - 2014).

A zona de expansão urbana da praia está se projetando para o setor turístico, fazendo-se necessário o monitoramento e conscientização ambiental por parte dos órgãos públicos e da população local, para que essa evolução não atinja a região de modo que venha degradar seus recursos naturais. Tais medidas não objetivam colocar obstáculos ou burocratizar o desenvolvimento da área, mas sim elucidá-los sobre a importância em conservar o meio ambiente local, para que não venha tomar o rumo da inconsequência, no que se refere aos danos ambientais, muitas vezes irreversíveis, oriundo de um desenvolvimento desenfreado e sem planejamento, no qual vem a prejudicar não só toda uma comunidade, mas uma região que se caracteriza por um grande atrativo turístico do município.

Para a definição das categorias ecodinâmicas na área de estudo, foi utilizada uma adaptação da classificação proposta por Tricart (1977). Esse elenco de correlações, análises e sínteses (Quadro 2 e Figura 10), permitiram compartimentar a área em unidades territoriais homogêneas de acordo com Souza (2000).

O município de São Gonçalo do Amarante é composto por uma população de baixa renda per capita, sendo de fundamental importância à preservação dos seus recursos naturais, pois tem grande potencial para atração de turistas, preservando o ambiente, o que melhoraria de forma direta e indireta a renda de milhares de pessoas no município. 


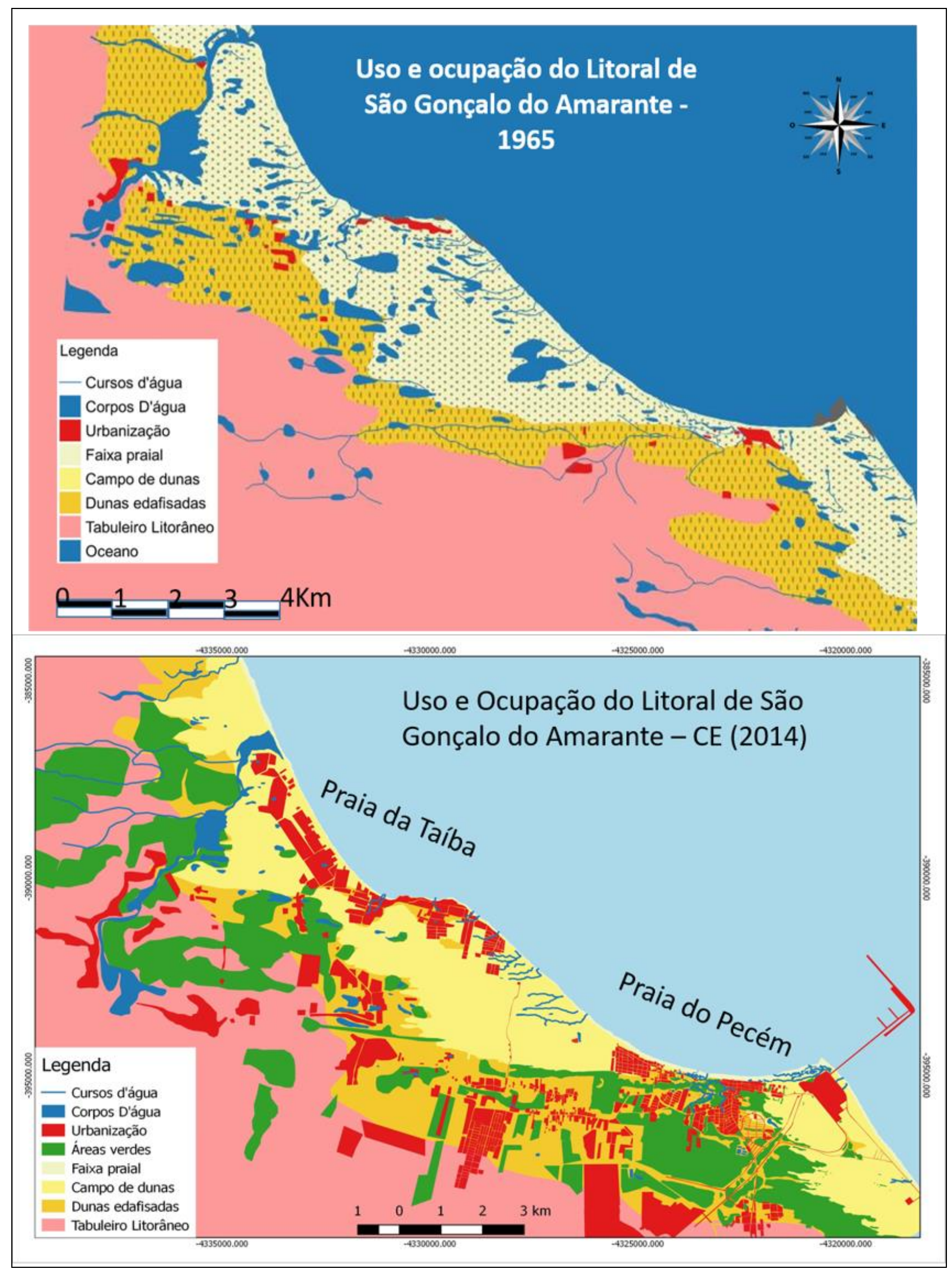

Figura 10. Evolução urbana das praias do Pecém e Taíba (1995 - 2014). Fonte: Portela (2017). 


\begin{tabular}{|c|c|c|c|}
\hline \multicolumn{2}{|c|}{ ECODINÂMICA } & Características naturais & Ecodinâmica \\
\hline $\begin{array}{l}\text { Planície } \\
\text { litorânea }\end{array}$ & 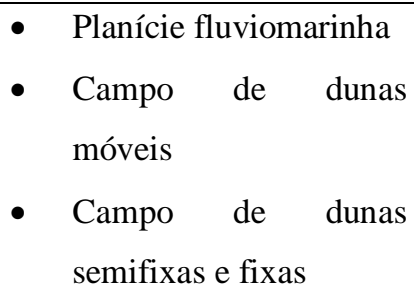 & $\begin{array}{l}\text { Linha de costa com dunas sob intensa } \\
\text { ação eólica. Planície fluviomarinha } \\
\text { com solos Neossolos Flúvicos e } \\
\text { vegetação do complexo litorâneo. }\end{array}$ & $\begin{array}{l}\text { Ambientes instáveis e } \\
\text { fortemente instáveis com } \\
\text { vulnerabilidade alta à } \\
\text { ocupação. }\end{array}$ \\
\hline $\begin{array}{l}\text { Tabuleiros } \\
\text { Litorâneos }\end{array}$ & $\begin{array}{ll}- & \text { Tabuleiros arenosos } \\
\text { - } & \text { Tabuleiros areno- } \\
& \text { argilosos }\end{array}$ & $\begin{array}{l}\text { Superfície predominantemente plana, } \\
\text { com declividade suave em direção ao } \\
\text { mar, presença de lagoas com } \\
\text { vegetação de tabuleiros modificados } \\
\text { pelas intervenções antrópicas. }\end{array}$ & $\begin{array}{l}\text { Ambiente estável com baixa } \\
\text { vulnerabilidade. Favorável a } \\
\text { expansão urbana e plantação } \\
\text { de culturas diversificadas. }\end{array}$ \\
\hline
\end{tabular}

Quadro 2. Compartimentação da ecodinâmica da área em estudo. Fonte: Souza (2000).

Para realizar a compartimentação ambiental da área, consistiu em foram realizadas interações temáticas através de sucessivos níveis de síntese, de acordo com as relações de causa e efeito. Esse mecanismo de correlação interdisciplinar conduziu à identificação da estrutura e da dinâmica dos espaços diferenciados para a conclusão da análise, onde esses dados foram estudados de forma integrada com o estudo as unidades ambientais, resultando na ecodinâmica da área de estudo.

\section{CONSIDERAÇÕES FINAIS}

A zona de expansão urbana da praia está sendo orientada para o setor turístico, fazendo-se necessário o monitoramento e conscientização ambiental por parte dos órgãos públicos e da população local, para que essa evolução não atinja a região de modo que venha degradar seus recursos naturais. Tais medidas não objetivam colocar obstáculos ou burocratizar o desenvolvimento da área, mas sim elucidá-los sobre a importância em conservar o meio ambiente local, para que não venha tomar o rumo da inconsequência, no que se refere aos danos ambientais, muitas vezes irreversíveis, oriundo de um desenvolvimento desenfreado e sem planejamento.

O município de São Gonçalo do Amarante é composto por uma população de baixa renda per capita, sendo de fundamental importância à preservação dos seus recursos naturais, pois tem grande potencial para atração de turistas, preservando o ambiente, o que melhoraria de forma direta e indireta a renda de milhares de pessoas no município.

Pode-se avaliar que o processo de uso e ocupação das praias do Pecém e Taíba alocou-se em áreas de grande fragilidade ambiental em virtude da gradativa expansão urbanística, como a identificação da ocupação de áreas de dunas, planícies de deflação e zonas de praia. A projeção 
dessa evolução urbana, bem como áreas destinadas para loteamentos, tem se dado para o setor Oeste do litoral, compreendendo principalmente a praia do Pecém.

\section{REFERÊNCIAS}

BRASIL. Lei $\mathrm{n}^{\circ}$ 9.985, de 18 de julho de 2000. Sistema Nacional de Unidades de Conservação (SNUC). Brasília, 2000.

. Constituição Federal de 1988. Brasília, 1988.

. Decreto 24.643 de 10 de junho de 1934. Código das Águas. Brasília. 1934.

. Decreto 23.793 de 23 de janeiro de 1934. Código Florestal Brasileiro. Brasília. 1934.

. Lei Federal $\mathrm{n}^{\mathrm{o}} 7.661$ de 16 de maio de 1988. Institui o Plano Nacional de

Gerenciamento Costeiro (PNGC). Brasília, 1988.

BRASIL.

Disponível

em

<http://www.mma.gov.br/estruturas/250/_publicacao/250_publicacao30082011035301.pdf>.

Acesso em 27 set. 2016.

BRITO, Francisco A.; CÂMARA, João B. D. Democratização e gestão ambiental: em busca do desenvolvimento sustentável. Petrópolis - RJ: Vozes, 1998.

CEARÁ. Anuário estatístico de 2012. Secretaria do Planejamento - SEPLAN. Fortaleza, 2012. . Anuário estatístico de 2003. Fortaleza: [s.n.] 2003.

. Decreto $\mathrm{n}^{\circ} 25.417$ de 29 de março de 1999. Dispõe sobre a criação da Área de Proteção

Ambiental - APA das Dunas da Lagoinha. Paraipaba, Ceará, 1999.

Decreto $n^{\circ}$ 25.416, de 29 de março de 1999. Cria a APA do Estuário do Rio Curu, unidade de conservação de uso sustentável. Paraipaba, Ceará, 1999.

CRISTOFOLETTI, Antônio. Análise de sistemas em geografia. São Paulo: HUCITEC, 1979.

DIEGUES, Antônio C. O mito moderno da natureza intocada. São Paulo: HUCITEC, 1996.

IBAMA. Instituto Brasileiro do Meio Ambiente e dos Recursos Naturais Renováveis. Disponível em <http://www.ibama.gov.br/>. Acesso em 25 mai. 2015.

IBGE. Instituto Brasileiro de Geografia e Estatística. Disponível em <http://www.ibge.gov.br/home/>. Acessado em 02 jun. 2015.

MORAES, M. V. A. R.; LIMA, I. M. de M. F. Análise Geomorfológica a Partir de Dados SRTM: Município de Teresina, Piauí. Revista Equador, v. 4, p. 951-960, 2015.

MORAIS, J. Onofre de. Processos e Impactos em zona costeira, Geologia do Planejamento Regional. Revista de Geologia. Universidade Federal do Ceará. Vol. 9, Fortaleza, 1996. 
PORTELA, João Paulo. Análise Ambiental do Município de Paraipaba-CE. Universidade Federal do Ceará. 2009. 164f. Dissertação (Mestrado em Geologia). Fortaleza, Ceará, 2009.

PARAIPABA. Lei orgânica do município. Prefeitura Municipal de Paraipaba, 1990.

ROCHA, Juliana G. Aspectos socioambiental e modelo de gestão em unidade de conservação municipal, estudo de caso: Juazeiro do Norte. Universidade Estadual do Ceará. 2004. Monografia (Especialização em Gestão ambiental) - Universidade Estadual do Ceará. Fortaleza, 2004.

SEMACE. Superintendência Estadual do Meio Ambiente. Programa de educação ambiental do Ceará. 2. ed. Fortaleza: SEMACE, 2003.

. Estação Escológica das Dunas do Pecém. Disponível em <

http://www.semace.ce.gov.br/2010/12/estacao-ecologica-do-pecem/>. Acesso em 23 mar. 2017.

SOUZA, Stella T. A saúde das praias da Boa Viagem e do Pina, Recife - PE. Recife, 2004.

Dissertação (pós-graduação em Oceanografia). Universidade Federal de Pernambuco, Recife, 2004.

UNESCO. Coasts: Managing Complex Systems. Enrivonment and Development. Briefs. United

Nations Educations, Scientifc and Cultural Organization. Paris, 1993, 16p.

VASCONCELOS, Fábio P. Gestão Integrada da Zona Costeira: Ocupação Antrópica desordenada, erosão, assoreamento e poluição ambiental do litoral. Fortaleza: PREMIUS, 2005. Modelos de referências:

Recebido em: 05/10/2017

Aceito para publicação em: 27/11/2017 